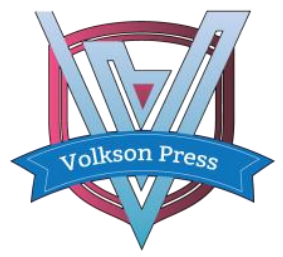

Economics, Finance and Statistics (EFS)

DOI : http://doi.org/10.26480/icefs.01.2018.43.47

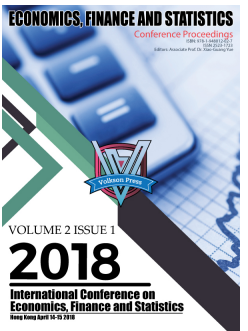

\title{
STUDY ON THE INTEGRATED DEVELOPMENT OF NEW MEDIA ART AND PUBLIC
} ART

\author{
Ran Xiao*, Xiaoxiao Zeng, Jing Chen \\ Huazhong University of Science and Technology, Luoyu Road 1037, Wuhan, China \\ *Corresponding Author Email: ran818@qq.com
}

This is an open access article distributed under the Creative Commons Attribution License, which permits unrestricted use, distribution, and reproduction in any medium, provided the original work is properly cited.

\section{ARTICLE DETAILS}

\section{Article History:}

Received 12 March 2018 Accepted 12 April 2018 Available online 15 May 2018

\section{ABSTRACT}

The constant emerging of front-line science and technology has driven the development of modern art design, and the manifestation pattern of traditional public art can no longer satisfy the need of modern city development as well as public cognition and aesthetics, so it is faced with the severe challenge of transformation. Under the support of digital technology, the combination of new media art and public art has endowed the traditional public art with a brand-new creation form, manifestation pattern and participation experience via the characteristics of multimedia integration and interaction, bringing about subversive changes. Meanwhile, more possibilities are added to the construction of urban public space.

\section{KEYWORDS}

New Media, New Media Art, Public Art.

\section{INTRODUCTION}

Public art appeared in America in the 1960s as a cultural concept of the contemporary art. Different from environment sculpture in a general traditional concept, it has a close relationship with the development of the city [1]. Based on a study, the practical function and meaning of modern public art have already turned into the carrier of reflecting the cultural spirit of contemporary cities and the environmental quality of cities in most cases, and it seems quite urgent and necessary to study the development of urban public art [2]. Under the background of digital era, the integration of new media art has brought about subversive changes to the development of public art, and the propagation characteristics of multimedia integration and real-time interaction have endowed public art with a brand-new manifestation pattern, participation experience and aesthetical feature [3]. At the same time, for new media art, public art has also expanded new application areas and cultural semantics, making new media art more open and diversified [4].

\section{INTEGRATION BACKGROUND}

\subsection{The Inevitable Result of Era and City Development}

People have many descriptions about the present era, such as computer era, digital era, information era, and internet era, but all of them are the same in essence [5]. The appearance and extensive application of computer, internet and digital communication equipment have greatly expanded the category of people's exchange of information, thoroughly changed human being's survival mode, and brought the era to an unprecedented digital information age [6]. With the continuous improvement of the era and society, the increase of substance level has triggered a new appeal for culture in the public. At present, economy is no longer the only criterion to measure whether a city is developed, and the cultural atmosphere of the city centering on cultural connotation and spirit has become an important index for city enchantment and development gradually [7]. (p.89-92)

As a carrier of cultural transmission, public art plays a role of propagating spirit, era and aesthetical concepts at multiple dimensions in the public space and can reflect the material civilization and spiritual civilization of a city as well as the history and future of the city [8]. The pattern of traditional public art cannot satisfy the need of era development and city development anymore at the present stage, and the digital transformation of public art is extremely urgent.

\subsection{Integration of Technology and Art}

The rapid development of science and technology has promoted the development of various industries, and the manifestation pattern of traditional public art is also faced with the severe challenge of transformation. The digital technology turns into a major expression means of modern art design, and its forms become increasingly diversified. The interactive and nonlinear operation of technology as a medium has also brought about a series of changes to traditional art design subjects in viewing patterns, expression means and creation ways [9]. Besides, the boundary among artists, viewers and artistic works becomes indistinct.

The development of digital technology has promoted modern art design and helps us see the interactive relation between technology and art design [10]. At the same time, the new media art setting digital medium as the means and internet as the propagation and display platform is born at the right moment. One of the differences between new media art and traditional art is that the development of the former relies on the development of new technology and theories, showing a technology characteristic of "keeping pace with the times". This is what modern public art lacks. By combining front-line high-tech means with innovative materials, the integration of new media art has opened up a new creation field for public art [11].

\subsection{Transformation of Public Cognition and Aesthetics}

In the contemporary complex social structure, the impact of information and technology has made people's life style increasingly diversified, and the spiritual world begins to present a strong sense of discontent and sense of vitality [12]. It becomes harder and harder to meet people's needs for culture and art, and the public aesthetic psychology and aesthetic perception are also changing [13]. In the past, public art was often passively received with pedagogical meaning, and the public almost had 
no choosing and changing rights. Besides, only one-way information dissemination exists in artistic works. The extensive spreading of information in the digital era has changed the traditional way of art appreciation in the public. With the continuous awakening of humanistic consciousness, the public hopes to transform the pattern of passively receiving art into initiative art appreciation, and even to change or create art. Hence, the works present a tendency of two-way communication. "Making all experiences a popular style" is the major feature of new media art, and its built-in public attribute happens to hold the same view with public art, so the "linkage" of two artistic forms seems quite natural.

The integration of new media art and public art is not only the product of era development but also the reflection of social spirit. At the same time, it also represents the public demands in cities. The development tendency of contemporary art is integration, and the integrated development of new media art and public art as well as the cross-disciplinary and crossboundary integrated development will become the development tendency of art in the future.

\section{BRAND NEW FEATURES}

New media art can provide more choices for the expression of public art, and the new concept brought about by it will inevitably influence the creation and expression of public art. The public new media art works created by the integration of these two are endowed with more features.

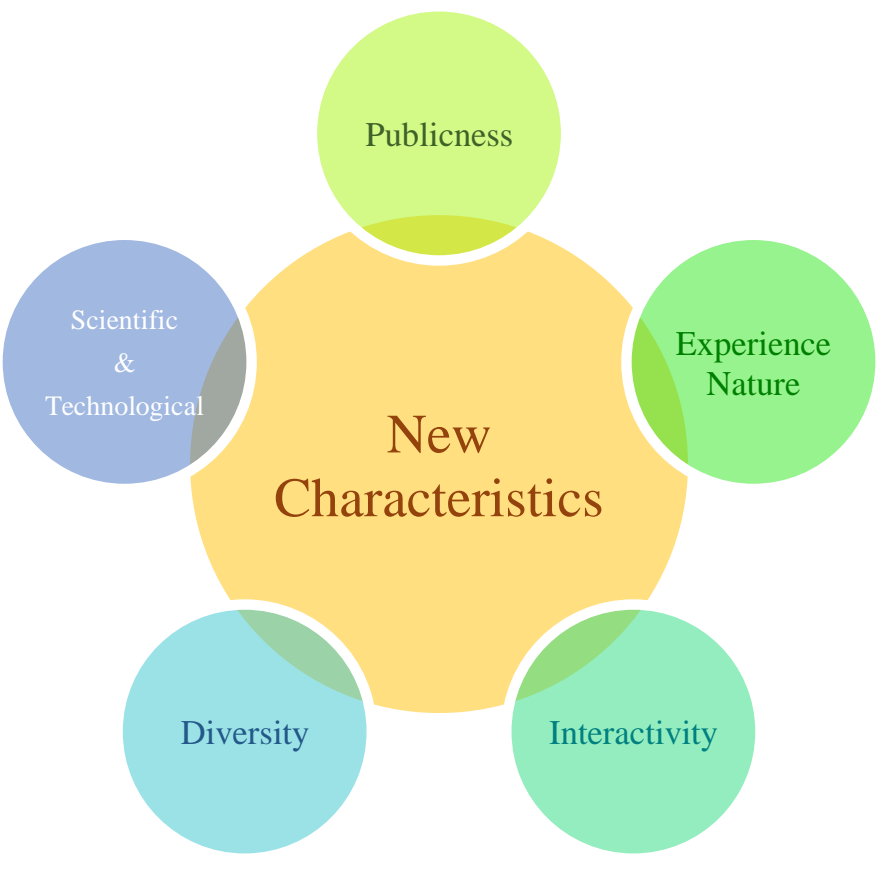

Table 1: New Characteristics of the Combination of New Media Art and Public Art

\subsection{Publicness}

The publicness is the essential attribute of public art. After new media art is integrated into public art, this attribute is still retained [14]. The publicness mentioned here is reflected not only in the public sharing and public participation layer of works but also in the aspects of public cognition degree, popular will, spiritual ideals, and public discourse power of selecting and operating the works. The publicness of the place where modern public works are put is influenced by new media art the deepest. The traditional public art emphasizes that the place where modern public works are put should be a free and open space that faces the public. After new media art intervenes, the context of "public place" is broadened. It not only includes the public place of a real space, but also includes the virtual place established by network platforms. New media art can create a broader spatial place and present different time dimensions. Hence, it possesses infinite extensibility in both space and time dimensions. After new media art intervenes, public art can better play the role of media dissemination via its information platform, and then influence public communication and public culture, giving more connotations to the publicness of public art.

\subsection{Scientific and Technological}

The technological nature is the core feature to distinguish from traditional public art after new media art is integrated into public art. The medium in new media art can also be called intermediary, i.e. the material and tool used by people in information dissemination and exchange, and more forms will be evolved with the development of science and technology, so the development of new media art cannot be separated from the development of science and technology. In other words, the technology motive has provided soil for new media art to take root and thrive as well as the sky for new media art to grow and soar [15]. Hence, contemporary public art is also endowed with technology characteristic, and intermediary materials based on digital technology are applied as the creation material in most cases, such as technological means and platforms including LED/LCD display, computer, sensor, internet, and communication tools; computer programming technology, augmented reality technology, virtual reality technology, shadow casting technique, and interactive system. Steps like digital modeling, circuit debugging and arrangement, software testing, etc. are needed in the creation process. At the moment of work presentation, several technical expression forms covering graph, image, game, music, and installation art are integrated.

\subsection{Experience Nature}

Public art is the product of social culture. With the appearance of experience economy, user experience and experience design, the experience nature of public art has also turned into the focus of attention in the public [16]. The experience nature of public art refers to the direct experience produced by the audiences through five senses and mentality when appreciating and participating in the works, and it means the direct exchange between the audiences and works. Traditional public art is dominated by visual sensory experience and aims to make the audiences accept the "beauty" of works. It is a kind of one-way information spreading, and the experience form is single. After new media art is integrated, diversified experience forms are generated, and the designer can blend auditory, tactile, smelling and even gustatory experience into the work. Moreover, the static visual experience of traditional artistic works can also turn into dynamic visual experience through image technology, making the audiences feel the contents of the work in an immersive way. By setting the audiences of artistic works as the service objects, treating the audiences' participation in works as the creation goal, and satisfying the audiences' demands for works through the exchange between the audiences and works, the experience nature of contemporary public art is the specific portrayal of "people first" of contemporary public art works.

\subsection{Interactivity}

Interactivity means the multidirectional interaction and exchange among artists, works, audiences and display environment. It has fundamentally 
changed the social form of public art and enhanced the audiences' enthusiasm of participating in artistic creation. Interactivity is a valid certificate proving that public art serves the public, and its fundamental objective is to satisfy public needs. Interactivity not only means that the audiences can contact the works, but also indicates that the audiences can exchange and participate through artistic works. Moreover, they can even proactively change the manifestation mode of works, intervene in the designer's creation environment, and deconstruct and recombine the works. Here, interactivity also includes interaction between artistic works and surrounding environment. The original form of works will change correspondingly with the alteration of surrounding environment, and a new work can be created. The integration of new media art and public art has realized multidirectional information transmission of works. The openness of platform brought about by interactivity has provided an extensive participation degree for mass culture and city culture, walked away from the self-speaking privacy and sense of narrowness of traditional artworks, and enhanced the cultural transmission influence of modern public art

\subsection{Diversity}

The diversity after the integration of new media art and public art is reflected in three aspects covering manifestation pattern diversity, technological means diversity and media material diversity of artistic works. In terms of technological means, multiple technological means are used in the creation process of artistic works after the two are integrated, such as computer technology, image technology, virtual reality technology, augmented reality technology, holographic display technology, network technology, telepresence technology, mechanical power technology, interactive sensor technology, artificial intelligence technology, etc. As for the artistic expression form, multiple artistic expression forms are integrated and intersected in new media art, such as installation art, film and television art, landscape art, architectural art, animation art, sound art, graphic image art, biological art, nano art, virtual art, bionic art, etc. In terms of the media materials applied, artistic works of integrating these two have applied digital media including computer, projector, display, sensor, sound device, mobile communication equipment and internet on the basis of using creation materials for traditional public art works, and different sense organ forms are utilized to bring about more diversified experiences to audiences.

\section{DEVELOPMENT PROCESS}

\subsection{Germination Period}

The integration of new media art and public art began to germinate with the "kinetic art" emerging in Europe at the beginning of the 1920s. The kinetic art means the art school to realize dynamic expression of works with mechanical components by utilizing mechanical means like natural factors or motor. The Russian artist Naum Gabo (1920) created the first kinetic sculpture "Standing Wave" in art history by utilizing wastes, electromagnet and peeler in the phone factory. The metal bar is driven by the motor in the work, and a stereoscopic visual effect is formed in the rotation process. This work has broken the history of thousands of years that artwork remains motionless. At the same time, it is also the reflection of artistic creation material innovation.

In 1922, László Moholy-Nagy (1922) put forward in a statement, "The audiences should actively participate in the work and become a part of the work, rather than watch passively. The work will change correspondingly according to the audiences' participation." The proposal of such interaction between works and audiences has also provided artistic guidance for the integration of these two at an early stage.

\subsection{Developing Period}

After the 1950s, the Second World War was over. Various belligerent states suffered a heavy setback and drove the third technological revolution represented by the application of electronic computer technology in the process of vigorously developing industries and reconstructing cities after the war, which changed people's life style and hastened new artistic expression forms. More and more artists and scientific workers began to study and create interactive public art works. Research teams of integrated art with the purpose of "combination of art and technology" appeared in multiple places centering on Europe throughout the world.
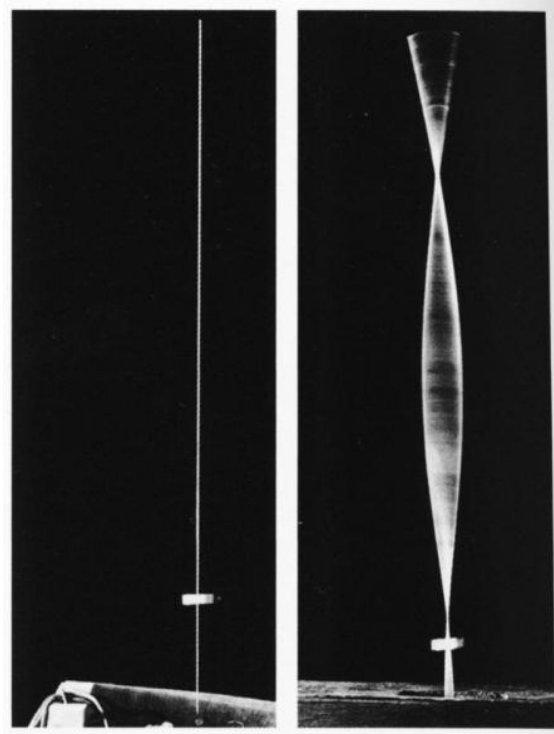

Figure 1: Standing Wave .Naum Gabo.Russia.1920.

In 1961, the first work integrating new media art and public art in a true sense appeared in Belgium, and it is "space mechanics - the Cybernectic Tower of Liege" which was created by the Hungarian French artist Nicolas Schoffer. This work is composed of 66 reflectors driven by computer, 33 rotating shafts, reflection of light and sound, etc. Factors in the surrounding environment including light, sound, humidity and air pressure are fed back to the design program with 120 color projectors, phototube, hygrometer, barometer and sensor. The thermometer and humidity sensor will project red light beams in cloudy days, and project blue beams in sunny days. Besides, this work also includes sound program, and the interaction of mobile sculpture and dance music is formed. This work becomes the token of modernized cities in the 1960s. At the same time, a great influence has been produced on technology application, creation concept and manifestation pattern of new media art and public art works in the future.

\subsection{Prosperous Period}
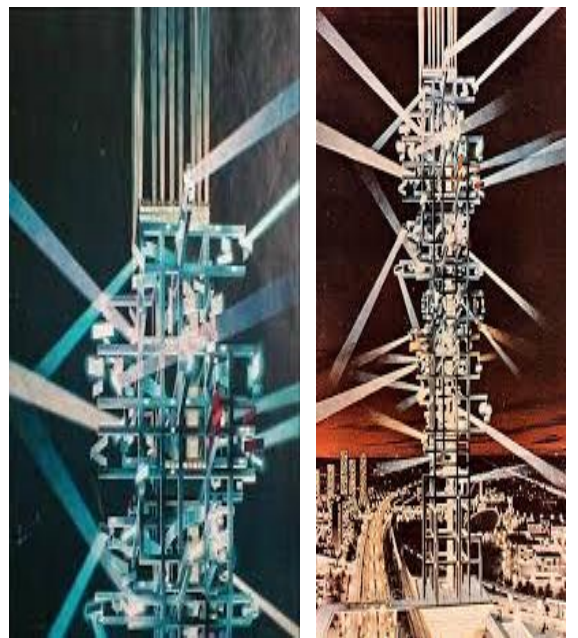

Figure 2: The Cybernectic Tower of Liege.Nicolas Schoffer.1961

After the 1970s, new media art gained great development with the popularization of computer technology application. It reached the climax after 2000. The maturity of various techniques like virtual reality, holographic image, interaction technology, sensor technology, sensing technology and network technology has made it possible to permanently display some new media art works in plazas and parks of various developed countries. 


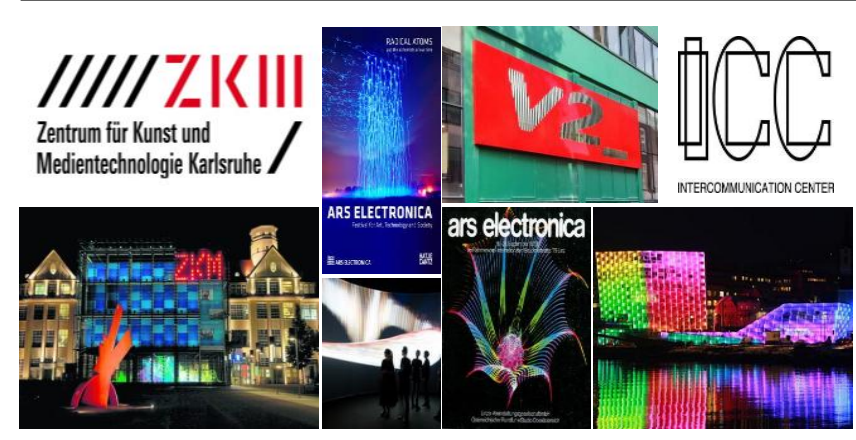

Figure 3: The International Famous Electronic Arts, Electronic Arts Festival and Exhibition Center

After the 1970s, by centering on Europe, various electronic art associations, electronic art festivals and exhibition centers around Europe have been produced. The establishment of these organizations has helped more people understand public art works of digital technology. Besides, technological means are developed more rapidly and applied more extensively to artistic works, thus the integrated development of new media art and public art is promoted tremendously. Many works moving towards public space have emerged in exhibition of numerous electronic art fields, and the establishment of activities and institutions has cultivated a huge batch of artists and scientific workers. Many works have been perpetually exhibited in urban spaces.

\section{EXISTING TYPES}

The combination of new media art and public art at the present stage has created many types of artistic works. Through generalization and summarization, they can be divided into 4 types including urban landscape, urban architecture, urban facility and virtual network. The specific introductions are as follows:

\subsection{Urban landscape}

Public new media art works of urban landscape include natural landscape and artificial landscape. The natural landscape means the artistic creation conducted with technological means of new media such as laser technology, shadow casting technique and interaction technology by setting natural ecology greening, water and rocks as the artistic carriers. The artificial landscape includes landscape type dominated by virtual landscape sculptures. It mainly refers to the artificial landscape sculpture type that conducts creation and expression with sound and light media such as projection, laser and LED by setting virtual objects like sound, light and image as the major forms under the support of digital technology.

The typical case of this type is "Crown Fountain" created by the Spanish artist Jaume Plensa in Millennium Park of Chicago. The work comprises two opposite brick walls of glass fall, and the walls have LED pictures controlled by computer. The artist took pictures of 1,000 citizens' faces of different skin colors and different ages in Chicago. These pictures are played at the speed of 6 pictures per hour, and pyramids and kids peeing will appear alternately. This work is fully integrated with the audiences. A good interaction is formed with the audiences at both spiritual level and entertainment level, and an artistic experience full of interest is brought to the audiences.

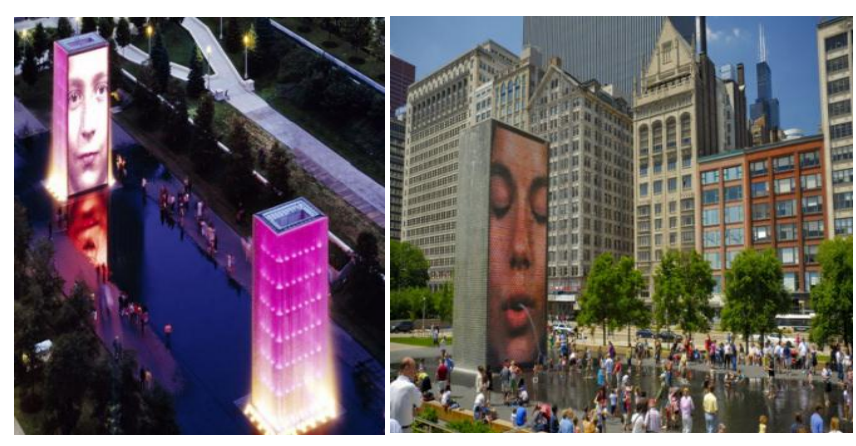

Figure 4: Crown Fountain. Millennium Park. Chicago.2004

\subsection{Urban architecture}

The work of urban landscape mainly means the artistic creation conducted with display technology such as shadow casting technique, sensing technology and led under the dominance of building elevation, top surface and ground by setting the building space of urban architecture as the carrier.

For instance, Refik Anadol, the artist of Los Angeles turned a wall in San Francisco 350 Mission into the public art work. This work is called Virtual Depictions, which transforms the parameters of this city into a surprising visual effect. In order to design the work, Anadol applied a database that is available to the public - urban traffic management, museum and housing data are SF OpenData, which will be updated on the internet at any time. Anadol combined it with the real-time application program interface (API) service of Twitter. These frozen data sets about citizens or pedestrians were combined with real-time positioning and 3D point cloud data of Twitter, and then they were made into dynamic visual images with VVVV and working software like Cinema4D, Rhino and Softimage XSI. The author aimed to create a new mode to make the public experience a digitized urban space by embedding new media art into the building. In this way, those invisible things will become visible, and contributions can be made to contemporary public art.

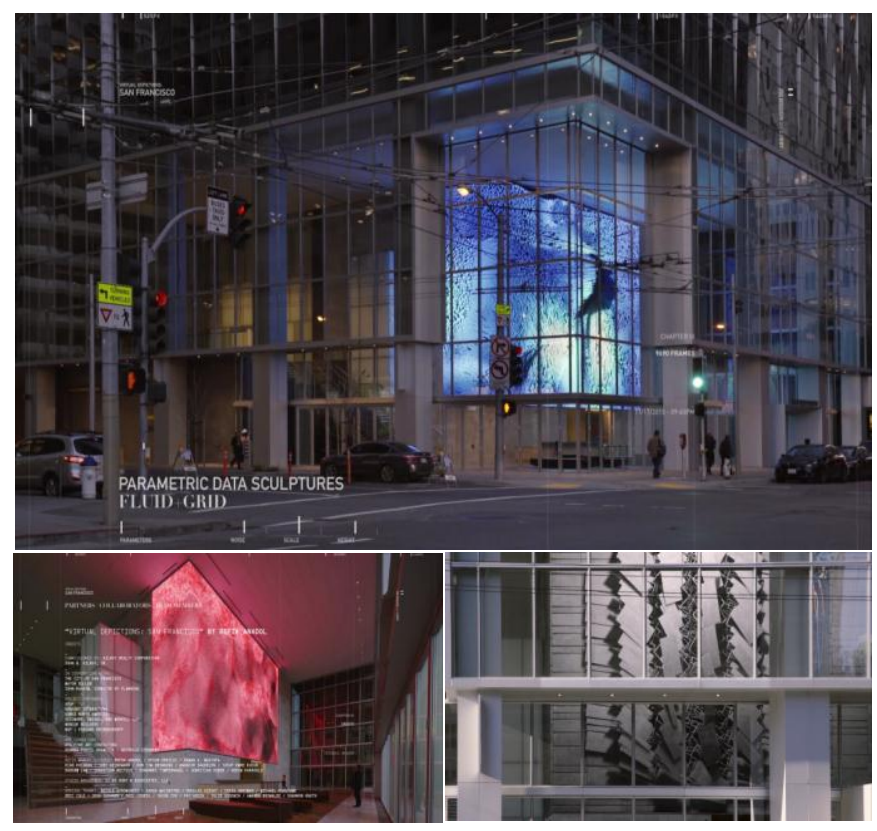

Figure 5: Virtual Depictions:San Francisco.2015

\subsection{Urban Facility}

The work of urban facility refers to the public art work placed at urban transport junctions such as urban public places including bus stop, subway station, railway station and airport, or public art work created under the support of urban public facilities like guide plate and urban furniture.

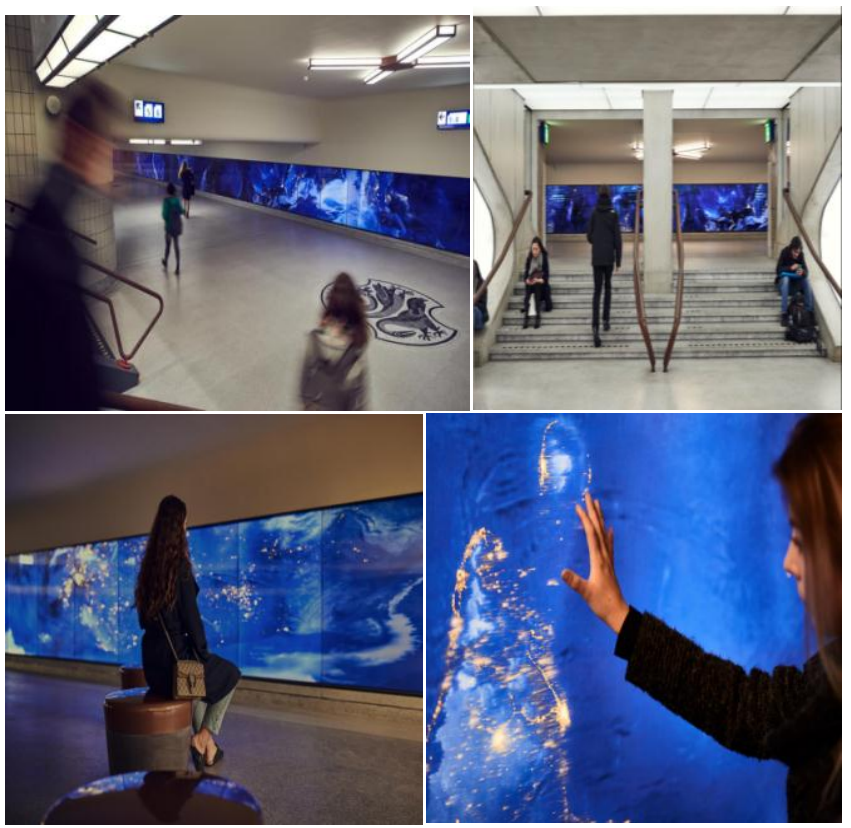

Figure 6: Space, Eindhoven Station, Netherlands, 2015 


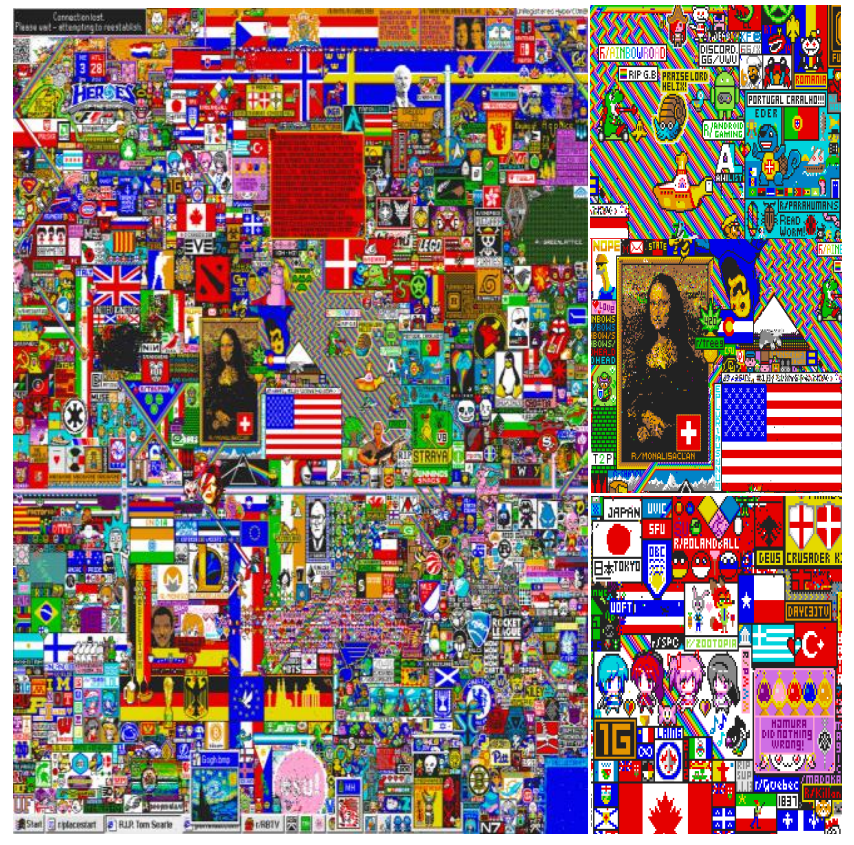

Figure 7: /r/place/ Pixel drawing, Reddit,Social Networking Site ,USA, 2017

The public art work with the length of 90 meters named "space" created by Studio Roosegaarde at Eindhoven Railway Station of Netherlands provides a charming visual exhibition effect for the public space of railway station through the abstraction of light and satellite images, and it is the cultural reflection of "City of Light" which is the title of Eindhoven. Studio Roosegaarde drew inspiration from nighttime satellite images of the earth, and light there represents human life and activities. "Light means communication and language", said Roosegaarde. "When passing by these artworks, you will experience a new dimension of light, just like what is observed by an astronaut in the earth orbit". This work has provided a window leading to the world for urban underground transportation hubs. With a hypnotic and calm atmosphere, by turning human life and progress into light, it has dexterously revealed human contacts in various places throughout the world.

\subsection{Virtual Network}

The public new media art work of virtual network sets internet as the display platform. As for the features of such works, they can be co-created by several persons in any place around the work, and various aspects of the work including creation materials, creation process and distribution platform can be completed with computer digital technology. Hence, it is an innovation type that completely overthrows the traditional public art. On the April Fools' Day of 2017, the largest online community in Europe and America and famous "American post bar" Reddit launched a public art creation activity in the section of $/ \mathrm{r} /$ place/. On a huge blank canvas of $1000 \times 1000$ pixels, including 1 million pixel points, every participant could choose to paint one pixel point with any color. Reddit users from different countries and regions showing a great difference in gender, age, race and religion participated in such a graffiti activity, and the entire activity only had three restrictions. The registration time of all participants should be earlier than 31 Mar. 2017, the participants must follow the rules of Reddit Community, and they could paint every 5 minutes $(10$ minutes at the beginning). The activity was started on 1 Apr. 2017, and ended on 3 Apr., lasting for 72 hours. Throughout the world, at least one hundred thousand people attended this activity. Every user could paint hundreds of pixel points at most. In order to form a meaningful image, several users should cooperate with each other, and various scripts were needed of course. But it was also some participants' purpose to destroy and cover other's image. The friction, conflict and coordination between different groups as well as the collision and twisting between cultural symbols were displayed incisively and vividly in the 72 hours.

\section{FUTURE PROSPECT}

The integration of new media art and public art has enriched the manifestation pattern of public art. More importantly, features of new media public art such as innovation, interestingness and interactivity have played an important role in establishing the urban cultural brand and activating the city's vitality. Such new-type contemporary urban public art will be the reflection of collective consciousness and individual reflection. It tries to bind the society, to make the audiences participate in expression, and to redefine the consistency and diversity of a series of problems in the society. With the application of new media and the increase of public participation, the whole public art and regions it serves have been truly connected into a dynamic organic entity(Chen Yao, 2015). The extensive participation of artists, designers, scientific workers and masses has greatly expanded the scale of design group and audiences, which will inevitably result in the transformation from quantitative change to qualitative change. Man's mental and material needs in the present society can be satisfied with creative art, design and technology, and the overall design level and technical capacity have gained significant progress.

The ultimate goal of public art should be the value belief to serve the country and society, and it is still the priority among priorities to study and explore how urban public art develops in the future.

\section{REFERENCES}

[1] Chen, L. 2007. New media art history. Tsinghua University press

[2] Collins, S. 2004. Out of darkness, light as public art. Leukemia, 18 (1), $120-125$.

[3] Chen, Y. 2015. Programs of Fairmount Park Art Association: An Overview of Philadelphia's Public Art. Art \& Design (2), 100-101.

[4] Finkelpearl, T. 2001. Dialogues in public art. Oral History Review,28 (2), 162-164.

[5] Hu, J., Le, D., Funk, M., Wang, F., Rauterberg, M. 2013. Attractiveness of an Interactive Public Art Installation. Distributed, Ambient, and Pervasive Interactions, 8028, 430-438.

[6] Jin, J.B. 2016. Features of Contemporary New Media Art. Tsinghua University Press.

[7] Gru, K., \& Yao, M.Y. 2005. Art intervenes in space. Guangxi Normal University Press.

[8] Li, S. 2007. The exploration of new media art in the post Image Era - the integration of digital media and contemporary art, Art \& Design Research, (4), 7-9.

[9] Lu, X.B., Huang, S. 2007. New Media Art - Integration of Science and Art. Science \& Technology Review, 25 (13), 30-33.

[10] Ren, B. 2008. The design of new media art and digital technology combined with the. Journal of Northwestern University: Philosophy and Social Sciences Edition, 38 (6), 191-193.

[11] Sharp, J., Pollock, V., Paddison, R. 2005. Just art for a just city: public art and social inclusion in urban regeneration, 42 (5), 1001-1023.

[12] Weng, J.Q. 2005. The Construction of Contemporary Art and Urban Public Space - Interpretation and Inspiration of Art Intervention Space. Art Research (4), 103-109.

[13] Zhang, F.C. 1983. Application of Optical Illusion in Design. Light Industry Press.

[14] Zhang, S.H. 2010. The Cultural Significance of Public Art as an Urban Landmark. Arts Criticism (1), 89-92.

[15] Zhang, X. 2010. Study on the Interactive Thoughts-Oriented Digital Public Art. Doctoral dissertation, Jiangnan University.

[16] Zhang, J., Lu. J.Y. 2016. Construction of Virtual Landscape Sculpture. Art Observation (10), 124-125. 